\title{
Study on the Foreign Publicity Translation of Marine Culture-Take Zhoushan for Example
}

\author{
Yuanyuan $\mathrm{Li}$ \\ School of Foreign Languages, Zhejiang Ocean University, Zhoushan, China \\ Yanbo Yao \\ School of Foreign Languages, Zhejiang Ocean University, Zhoushan, China
}

\begin{abstract}
The development of foreign publicity translation of marine culture is of great significance to the internationalization of Zhoushan Archipelago New Area. Based on Lasswell 5W mode (Harold Lasswell, 1948), this paper will combine some successful cases of foreign publicity translation of marine culture at home and abroad and analyze the present situation of foreign publicity translation of marine culture in Zhoushan Archipelago New Area by means of questionnaire surveys and the literature study on existing newspapers, periodicals and websites in Zhoushan. Accordingly, some suggestions are put forward to improve the deficiencies of the translation of marine culture in Zhoushan and innovate the ways in translating the marine culture, thus boosting the development of marine tourism economy and promoting the establishment of International Ecological Leisure Tourism Island (2016) in Zhoushan.
\end{abstract}

Index Terms - Zhoushan, marine culture, foreign publicity translation, Lasswell 5W mode, communication

\section{INTRODUCTION}

As an international tourism island, Maldives made use of its unique natural environment and created the slogan "always natural" and "one island with one characteristic", which make Maldives enjoy worldwide reputation and become a valuable example of ecotourism development by step by step's exploration. In recent years, with the support of the government policy, Hainan Island pays attention to the foreign publicity of local culture and the protection of natural environment, so that it can gradually meet the international standards. Judging from the measures that has been adopted by these two islands and the present situation of these two islands, the foreign publicity of the local culture contributes to their successful development in the international community, and the communication of the culture in the world is closely related to the translation of language. Therefore, the development of Maldives and Hainan Island has an essential reference to the international development of Zhoushan Island.

The new concept of making Zhoushan into an international ecological leisure tourism island was proposed according to the Outline of the $13^{\text {th }}$ Five-Year Plan (2016). Zhoushan is a city which is formed and development by the sea. It matters greatly how to highlight the unique charm of Zhoushan and build a tourist city with attractive marine characteristics for foreign tourists in the process of modernization and internationalization. The International Ecological Leisure Tourism Island, that is, under the premise of realizing the island tourism benefits, conforming to the code of ethics and local characteristics to develop the tourism. Its establishment and the breadth and depth of the foreign publicity of the local marine culture in Zhoushan are inter-related. First, human culture originates from the sea, and marine culture is formed by people's daily practice. Different from daily understanding of most people, marine culture is not a simple addition of ocean and culture, but an organic unity of two, which relates to integrity and distinct self-characteristics. It's also s kind of culture heritage which is different from the culture of river and the culture of land. At present, the communication and development of marine culture is mainly based on people's practical activities. And it takes mass media as carrier. Secondly, pushed by maritime power strategy, developing marine economy and culture is self-evident. Therefore, the high quality and high-efficiency translation of marine culture is particularly important. But in the process of translating marine culture, the available translation is relatively scarce. Moreover, there is hardly any relevant text in local newspapers and periodicals, and only a few local portals briefly introduce Zhoushan marine culture. In addition, the differences between Chinese and English and the sociality, regionality, and shareablity of marine culture greatly hinder the international exchange in Zhoushan and not conductive to Zhoushan to show its international image. (Chen Tao, 2013) Combined with Lasswell 5W mode, this paper will focus on analyzing the existing translation of marine culture so as to make some reasonable suggestions for the foreign publicity translation of marine culture.

\section{LASSWELL 5W MODE}

Compared with general translation, foreign publicity is a special form of translation which also has the function of publicity. What's more, the interdisciplinary attribute of foreign publicity translation further highlights its 
communication attribute.(Liu Yafen, 2010) At the same time, communication is a process in which communicator uses the public communication symbol of media to influence the attitude of general public and change their thought, thereby achieving a certain propose.(Wang Jiping, Wang Penjin, Pan Zhongjin, 2006) Huang Youyi believes that the translator's task is to translate Chinese into foreign language in an excellent way, and then express and deliver the viewpoints of China in the process of publicizing China. (2004)

\section{A. Background}

In 1948, Harold Lasswell, one of the communication study pioneers, published a paper called The Structure and Function of Communication in Society (Harold Lasswell, 1948). This paper puts forward a theory of communication process: (Who) $\rightarrow$ (Says what) $\rightarrow$ (In Which Channel) $\rightarrow$ (To Whom) $\rightarrow$ (With What Effects), 5W briefly. Lasswell stated that "Who" refers to control analysis, "Says what" refers to content analysis, "In Which Channel" refers to media analysis, "To Whom" refers to audience analysis and "With What Effects" refers to effect analysis. (Harold Lasswell, 1948)

\section{B. Content}

$5 \mathrm{~W}$ mode is focusing on communicator, message, medium, audience and effect. Communicator can be an individual or collective, it has the tasks of collection, processing, and delivery of information. Message, which consists of linguistic symbols and non-linguistic symbols, is the content of communication. Medium is material carrier, such as letter, telephone, newspaper, radio, etc. Audience is the object the destination of communication, such as readers, listeners, viewers, etc. Effect is the response of the audiences at all levels of its cognition, behavior and emotion. Its primary measure is whether the communication activity is successful or not. These five elements clearly indicate that the communication is a process with the purpose of trying to influence the audience. (Steinbury Sheila, 2006) In terms of some analysis, we can know that the communicator acts on the audience in the first four elements. However, the fifth element is the reaction of the audience to the communicator. Different from the concept of communication in one culture or language contained in Lasswell $5 \mathrm{~W}$ mode, the foreign publicity translation is a kind of communication activity which is carried out across different languages and cultures, but they two have common essences, that is, the process and the communication of information. (Yang, X, L, 2010) The above concepts fully prove the applicability and the reference value of Lasswell $5 \mathrm{~W}$ mode for foreign publicity translation.

\section{Application}

Lasswell 5W mode is the earliest mode which divides the communication process into five elements and defines five research fields accordingly. It effectively describes and plans the communication research. For example, the advertising achieved the advertisement of products or service by analyzing the contents of the five elements. The emergence and development of Lasswell $5 \mathrm{~W}$ mode is of great significance to the field of communication and journalism. Therefore, according to the five elements of Lasswell $5 \mathrm{~W}$ mode, the author will analyze the current situation of the foreign publicity translation of marine culture in Zhoushan Archipelago New Area from two aspects: communicator and audience.

\section{Analysis on the CURREnt Situation of Foreign Publicity Translation in Zhoushan}

At present, there are two main ways to publicize marine culture in Zhoushan. One is two local portals, the others is various activities on the theme of marine culture, such as Ocean Cultural Festival, International Islands Tourism Conference, World Oceans Day and so on. What's more, the publicity activities of Zhoushan marine culture will be held regularly in local cultural center. The function of the two local portals and those activities which are related to marine culture and the publicity of Zhoushan will be analyzed specifically as follows:

\section{A. Starting from the Angle of the Communicator}

Communicator plays a leading role in the first four elements of Lasswell $5 \mathrm{~W}$ mode, whose importance is equal to the translator in foreign publicity activity, that is to say, every correct choice made by communicators play an important role in foreign publicity translation. And to settle the problems from the primary causes is more quick and reasonable than to have a solution.

1. Communicator

At present, the communicator of marine culture in Zhoushan can be mainly divided into two parts: governmental and non-governmental communicator. The governmental communication can also be divided into full-time and part-time communicator. Full-time communicators are those people who enter the government through national examination in order to engage in publicity or translation work. But these people are mainly work on government affairs. This causes the prospective effect of marine culture publicity is decreasing from the source. Part-time communicators are social organizations, enterprises, in-service teachers, college students and the people who are interested in publicity or translation. For example, people who came to Fuji Island and interested in sharing it with others can write his or her feelings in local portal. Thus, the professionalism and comprehensiveness of the article will be lower at the same time. The local people who introduce Zhoushan to other areas' people are the main force of non-governmental translators. And because of the small number and the big mobility of non-governmental translators, there is a lack of social 
coverage in internal communication. The low social coverage is displayed by limited publicity and insufficient influence. The shortcomings of both lead to the big discount of communication effect.

2. The contents of the communication

The main contents of the foreign communication of Zhoushan marine culture are marine culture tourism, seafood and local folk customs. The home page of Zhoushan network consists of brief introduction of Zhoushan, seafood, marine economy, travel, and current affairs in Zhoushan. But the translations in each block just simply mention Zhoushan marine culture so as to lack substantive. Take the travel block as an example. In an article entitled famous sand beach scenic spots in Zhoushan, the translator devotes a large chunk of the text to describe soft sand, blue sea water, sunshine and other common things of beach. And refers to The Marine Culture Reader published by the publicity departments of Zhoushan municipal government, Zhoushan marine culture also included marine science, marine literature and art, coast defence and so on. The comparison between the two directly reflects the communication contents of Zhoushan marine culture is lacking of information, so that the translation cannot meet the various needs of the audiences. Further, the translation weakens the effect of the foreign publicity of Zhoushan marine culture.

3. The communication media

As a tool and a kind of means in the process of publicizing information, the correct choice and rational use of the media play an important role in promoting the foreign communication of different things. And with the development of modern society, the foreign development of various things becomes more and more dependent on the mass media. However, after browsing Zhoushan local newspapers, periodicals and websites, the author found that the scope of the media that the foreign communication of Zhoushan marine culture relies on is very narrow. There are only two websites that involve the translation of marine culture, namely, Zhoushan municipal government website and Zhoushan network. As for local newspapers and periodicals, there is hardly any related translations about marine culture. To sum up, the deficiencies of local media greatly hinder the communication of Zhoushan marine culture and lower the popular rate of the translations.

4. The effects of existing texts

The effects of publicity should base on whether the texts are proper and professional or not. And the text is related to the translator. On the one hand, one point should be affirmed is that the set of marine culture column in the two local websites is beneficial to the development and external change of Zhoushan marine culture, especially in Zhoushan tourism. It should be encouraged and enlarged. But in the other hand, according to the analysis of the existing translations of marine culture, there are still many problems in the websites as follows.

a. Language problems

Many language problems can be found in two local portals, such as misspelling, improper use of the punctuation marks, grammatical errors and so on. For example, the sentence Zhoushan has explored the cruise lines between Korea, Japan, Southeast Asia, Taiwan and Hong Kong such countries and regions, there are some grammatical errors in this sentence. The word "explore" should be used in the form of present participle. And the two words "between" and "among" should be distinguished clearly so as to increase the readability. Moreover, the error appeared in the second sentence if you want to fully experience Zhoushan seafood delicacies, not-to-be-missed Zhoushan Seafood Delicacies Festival holds in the July every year directly lowers the fluency of reading and weakens the explicitness of the passage. It's much better to use "not miss" instead of "not-to-be-missed".

b. Unclear expression of the translation and the delayed information

The delayed information of the contents occurred in the two websites made the audiences lose their interests in reading. What's worse, most of them are all at sea with the unclear expression of the translation. Here are also some examples to illustrate the above problems. Peach blossom meeting, a kind of traditional folk activity in Zhoushan Peach Island, is established for praying for sufficient rainwater and rich harvest in dry seasons. But one of the translations translates it as Taohua Hui. Taohua Hui is a kind of expression in pinyin (Chinese phonetic alphabet), which causes the lose of articulation in the text. The reader will fell confused about the meaning of this word. The improper use of the second sentence is communicating the delayed and wrong information. The next mentioned Shenggu Temple maybe is the lowest temple in elevation around the world. As a kind of publicity material, every word that appeared in the text should be accurate and professional. Through literature and online searches, the lowest elevation temple in China is Fujian Dongming Temple. And the word "maybe" is an expression of uncertainty. Undoubtedly, the credibility of this text is reduced too.

c. Brief translation and scarce resonance

It's easily to find that most of translators get used to translating according to their inherent thought, so it's difficult to arouse the spiritual resonance between translator and reader. A web page briefly introduced the statue of Cai Bogong which is built in Miaozihu Island. There is only little description about this statue's location and appearance. But according to local people's narration and historical document, we can know that the statue of Cai Bogong is also known as the statue of liberty. As we all know, the statue of liberty is one of the symbols of America. So the introduction of Cai Bogong can be written with the statue of liberty in the East. If the translator connects the two statues together, the reader will have a better understanding of the translation. And at the same time, the close relationship between the reader and the translation will be built. 
The main purposes of foreign publicity translation are to influence the audience, make the audience interested in the contents of the translation and further understand the relevant contents of the subject information. Through analyzing some successful cases of cultural communication, it's not difficult to find that the subject of the publicity is more on discovering audience's needs and following their thought so as to form the unique features.

1. Questionnaire method

In order to know the audiences' ideas, a questionnaire was conducted among 100 foreigners by random sampling from the people who live in or have lived in Zhoushan. The questionnaire consists of four parts with nine questions: the understanding of Zhoushan marine culture in the form of open-ended questions, their ideas and suggestions on Zhoushan marine culture in the form of closed-ended questions. In this way, the popular rate and the achievements of Zhoushan marine culture can be known more specifically. The content analysis and the results of the questionnaire are as follows.

Firstly, only $17 \%$ of the subject said that they had heard Zhoushan marine culture, and all of them came into contact with it only once a month or a week. Secondly, $85 \%$ of the respondents said that the translations of the text without real understanding must be avoided, and most of them showed that they get tired of the existence of the problem easily, while the remaining respondents thought that the translator should pay attention to avoid non-uniform version of proper noun, rigid translation and the expression and the expression English in Chinese phraseology. Finally, in terms of the suggestions given by the respondents, $42 \%$ people thought that the translation should be as clear as possible, and the proper nouns involved in the article ought to be explained in the form of annotation. 35\% people thought the most important thing is showing the features of a translation and $23 \%$ people put the decrease of language problems in the first place.

2. Results analysis

Based on the Lasswell 5W mode and combined with the perspective of communicator, first, the results show that the popularization of the marine culture in Zhoushan is low. It means most of communicators have a relatively low understanding of Zhoushan marine culture and not fully comprehend the characteristics of Zhoushan marine culture. Second, the scope of the communication is narrow and the way of communication is too single, this has resulted in an obstruction of the audiences' information acceptance. The feedback of the questionnaire shows that readers suggest that the translation should identity their characteristics which including language and custom background, assess their objects and needs, and plan for subgroup with the audience. (Philip Rubens, 2000) And when people are spreading Zhoushan marine culture, the lack of integrity, accuracy and characteristic culture in translations will lead to poor publicity.

\section{SugGeStions AND COUNTERMEASURES}

George Gerbner (1967), the founder of the cultivation theory, expanded Lasswell 5W mode in 1956 to focus attention on perception and reaction by the perceiver and the consequences of the communication. (Berger, 2007) Only communications think critically and use the mass media reasonably can translations reach one plus one is greater than two results. Based on the analysis of the five elements of Lasswell $5 \mathrm{~W}$ mode and present situation, the translations should satisfy readers' reading requirement, focus on the improvement source, so as to show attractive information for the audiences.

\section{A. Basic Translation Ability}

The language problems in the translation directly reflect the basic competence of the translator. At the same time, the first impression that the translation gives to reader comes from the basic aspects, so the correctness of the language is quite important. It is as if someone has messed up the wires of the phone so that only incoming phone calls can be received, and the outgoing calls be made, or just the opposite. Thus, translators should strengthen their own language skills, examine carefully and proofread the content of the translation seriously. For governmental translators, the government should arrange theoretical courses regularly to improve their professional quality. Staff themselves ought to pay more attention to their works. For non-government translators, first of all, the government should encourage them to engage in more social activities which are related to marine culture. Equally, local people's enthusiastic participation is the best reaction.

\section{B. Cultural Consciousness}

The internal communication is the basis of the external communication, and the external communication is the extension of the internal communication. (Liu, Y. F. 2010) Zhoushan marine culture is different from that in other coastal area. Zhoushan marine culture contains rich connotations, such as marine tourism culture, marine fishery culture, marine communication culture and so on. (Wang, W. H. 2009) Because the cultural confidence of communicators is based on their cultural consciousness, so in the process of publicizing Zhoushan marine culture, the communicator should not only include the translators, but also include the local people. Therefore, on the one hand, the communicator needs to develop their cultural awareness, humanity knowledge and aesthetic creativity. On the other hand, Zhoushan government should broaden the channel of communication of marine culture actively, organize the communicators to participate in various activities which is related to marine culture, and study related knowledge regularly, so that they 
can fully understand the characteristics of Zhoushan marine culture, deeply understand and correctly grasp the law of development of marine culture, root the marine culture in the heart, and better display the image of Zhoushan in the translation of external communication.

\section{Common Ground and Difference}

Seeking common grounds refers to the content of the translation should based on the common understanding of the two sides. Building a framework included emotion and the way of thinking that works on both sides. Reserving differences refers to the translation ought to highlight the bright spot and show the characteristics of Zhoushan marine culture, thus stimulating the interest of the foreigners to come to Zhoushan. The addition and subtraction should be used reasonably in order that the content of the translation is optimized. (Sun, F. 2014) The content of translation should close to the audiences' thought, language and reading habits by considering the audiences' feeling and solving their doubts. (Jia, Y. L. 2013)

\section{CONCLUSION}

Zhoushan Archipelago New Area, as the first national new area with the theme of marine economy, undertakes two strategies of regional and marine development. Marine economy and marine culture support each other and promote each other. On the basis of developing Zhoushan marine economy, the importance of publicizing Zhoushan marine culture is beyond doubt. The foreign publicity translation that looks at Zhoushan marine culture from the perspective of the audience and the communicator is helpful to display the image of Zhoushan as a characteristic tourist city and promote the construction of international marine ecological island in China. What's more, embodying humanistic care is also important.

\section{APPENDIX}

The questions of questionnaire:

1. Have you ever heard or known about Zhoushan marine culture?

2. Could you write some words about Zhoushan marine culture

3. How do you understand Zhoushan marine culture?

4. Have you ever joined some activities about Zhoushan marine culture? If you answer is Yes, please cite some examples.

5. Have you ever read some English versions about Zhoushan marine culture? And how do you find these versions?

Is there any version makes you feel confused?

6. Frequency: how often do you learn about Zhoushan marine culture?

7. In your opinion, which aspects that Zhoushan ocean culture's translation should pay attention to?

8. Choice: combining your reading, what's the biggest problem of English version as follows?
A. interpreting without clear understanding
B. there is no uniform translation among different versions
C. the translation is rigid
D. writing English in Chinese style

9. Will the wrong versions affect your opinion about Zhoushan and Zhoushan tourism?
A. not at all
B. a little
C. most

\section{REFERENCES}

[1] Arthur Asa Berger. (2007). Essentials of mass communication theory. San Francisco: Sage Publication.

[2] Chen Tao. (2013). An investigation and analysis on marine culture and characteristics of marine culture. Sociological Review of China, 5, 81-89.

[3] Harold Lasswell. (1948). The structure and function of communication in society. New York: Institute for Religious and Social Studies.

[4] Huang, Y. Y. (2004). Sticking to the "three close" principal foreign publicity translation. Chinese Translators Journal, (6)25, 24-25.

[5] Jia, Y. L. (2013). On how to improve the readability of foreign publicity translation based on punctuation. Chinese Translators Journal, 4, 110-112.

[6] Liu, Y. F. (2010). Translator's adaptation and selection: study on the process of publicity. In Liu, Y, F (Ed.), Publicity and publicity translation. Peking: Chinese people's Publishing House, 21.

[7] Philip Rubens. (2000). Science and Technical Writing: A Manual of Style. New York: Routledge.

[8] Steinbury Sheila. (2006). An introduction to communication studies. Cape Town: Juta \& Co.

[9] Sun, F. (2014). Translator's initiative in foreign publicity translation. Canadian: Canadian Social Science.

[10] Wang, J. P., Wang, P. J \& Pan, Z, Y. (2006). How to gain media publicity: operational guide publicity of public organizations. Peking: South Daily Press.

[11] Wang, W. H. (2009). The map of Zhoushan culture. Zhoushan: Ocean Press. 
[12] Yang, X. L. (2010). C-E translation for global communication: from a perspective of communication studies-with a case study on China Today. Shanghai: Shanghai International Studies University.

Yuanyuan Li is originally from Zhejiang, China. She is a junior student from Zhejiang Ocean University, China in 2019.

Yanbo Yao is originally from Zhejiang, China. She earned M.A. in linguistics from East China Normal University, China, in 2006, a visiting scholar at the University of Exeter in 2014. She is serving on the business English faculty at Zhejiang Ocean University, China. Her professional interests include teaching research, business English and translation. 